\title{
A20, a modulator of smooth muscle cell proliferation and apoptosis, prevents and induces regression of neointimal hyperplasia
}

\author{
Virendra I. Patel,* Soizic Daniel,* Christopher R. Longo, ${ }^{*}, 1$ Gautam V. Shrikhande,* \\ Salvatore T. Scali,* Eva Czismadia,* Caroline M. Groft,*,2 Tala Shukri,* \\ Christina Motley-Dore,* Haley E. Ramsey,* Mark D. Fisher,* Shane T. Grey, ${ }^{*, 3}$ \\ Maria B. Arvelo,* and Christiane Ferran*,4 \\ *The Immunobiology Research Center, the Division of Vascular Surgery and the Transplant Center, \\ Department of Surgery and the Division of Nephrology, Department of Medicine, Beth Israel \\ Deaconess Medical Center, Harvard Medical School, Boston Massachusetts, USA
}

ABSTRACT A20 is a NF-KB-dependent gene that has dual anti-inflammatory and antiapoptotic functions in endothelial cells (EC). The function of A20 in smooth muscle cells (SMC) is unknown. We demonstrate that A20 is induced in SMC in response to inflammatory stimuli and serves an anti-inflammatory function via

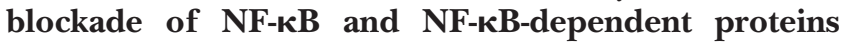
ICAM-1 and MCP-1. A20 inhibits SMC proliferation via increased expression of cyclin-dependent kinase inhibitors $\mathrm{p} 21^{\text {waf1 }}$ and $\mathrm{p} 27^{\mathrm{kip} 1}$. Surprisingly, A20 sensitizes SMC to cytokine- and Fas-mediated apoptosis through a novel NO-dependent mechanism. In vivo, adenoviral delivery of A20 to medial rat carotid artery SMC after balloon angioplasty prevents neointimal hyperplasia by blocking SMC proliferation and accelerating re-endothelialization, without causing apoptosis. However, expression of A20 in established neointimal lesions leads to their regression through increased apoptosis. This is the first demonstration that A20 exerts two levels of control of vascular remodeling and healing. A20 prevents neointimal hyperplasia through combined antiinflammatory and antiproliferative functions in medial SMC. If SMC evade this first barrier and neointima is formed, A20 has a therapeutic potential by uniquely sensitizing neointimal SMC to apoptosis. A20-based therapies hold promise for the prevention and treatment of neointimal disease.-Patel, V. I., Daniel, S., Longo, C. R., Shrikhande, G. V., Scali, S. T., Czismadia, E., Groft, C. M., Shukri, T., Motley-Dore, C., Ramsey, H. E., Fisher, M. D., Grey, S. T., Arvelo, M. B., Ferran, C. A20, a modulator of smooth muscle cell proliferation and apoptosis, prevents and induces regression of neointimal hyperplasia. FASEB J. 20, 1418-1430 (2006)

Key Words: NO $\cdot$ cell cycle $\cdot$ intimal hyperplasia

Proliferation of SMc, their acquisition of a synthetic, proinflammatory phenotype, as well as their recently recognized "high" resistance to apoptosis are central events in the pathogenesis of vascular lesions, including vein graft occlusion, postangioplasty restenosis and transplant arteriosclerosis (TA), an accelerated form of atherosclerosis (1-3). Restenosis occurs in $20 \%$ to $40 \%$ of patients within the first few months after successful angioplasty and is only delayed with stent implantation (4). Stent failure remains unacceptably high with restenosis incidence reaching $\sim 30 \%$ (4).

Novel therapies aimed at blocking SMC proliferation such as rapamycin/sirolimus-coated stents demonstrate promising clinical potential (5). However, this benefit is still insufficient particularly in diabetic patients, prompting the exploration of additional therapeutic leads (6). With the recent appreciation that atherosclerosis and restenosis may reflect failure in apoptotic pathways mediating regression of neointima, several proapoptotic strategies have been successfully explored in experimental models of neointimal disease including down-regulation of the antiapoptotic $b c l$ family member Bcl- $x_{L}$, inhibition of Survivin, a member of the inhibitors of apoptosis proteins family, overexpression of Fas ligand or increasing NO levels, a known apoptotic stimulus to SMC (7-11).

We hypothesize that a strategy combining anti-inflammatory/antiproliferative and proapoptotic effects in SMC could be optimal to prevent/treat neointimal vascular disease. We had previously shown that the zinc finger protein A20 is part of the endothelial cell (EC) response to injury. In EC, A20 serves a broad antiinflammatory function via inhibition of the transcription factor NF-кB and an antiapoptotic function

\footnotetext{
${ }^{1}$ Current address: Division of Vascular Surgery, University of Michigan, Ann Arbor, MI, USA.

${ }^{2}$ Current address: Cornell University School of Medicine, New York City, NY, USA.

${ }^{3}$ Current address: Arthritis and Inflammation Program, Garvan Institute for Medical Research, Sydney, Australia.

${ }^{4}$ Correspondence: Beth Israel Deaconess Medical Center, Research North Rm. \#370F, 99 Brookline Ave., Boston MA 02215, USA. E-mail: cferran@caregroup.harvard.edu doi: 10.1096/fj.05-4981com
} 
through inhibition of the initiator caspase 8 , both beneficial to contain vascular disease (12-16). NF-кB is also a critical effector of the SMC response to injury and is required for SMC activation and proliferation in vitro and for progression of atherosclerotic plaques in vivo (17). We reasoned that if A20 inhibits NF-кB activation in SMC, as it does in EC, its overexpression could positively affect vascular remodeling after injury by inhibiting SMC activation and proliferation. However, if A20 was to maintain its antiapoptotic function in SMC, its expression could increase SMC resistance to apoptosis and contribute to neointima formation. Indirect evidence from rat renal kidney allografts demonstrating a strict inverse correlation between the expression of A20 in SMC and the incidence of TA rather favored the "atheroprotective" potential of A20 in SMC (18).

In this study, we explore the function(s) of A20 in $\mathrm{SMC}$ and evaluate its effect on NF-кB activation, cell proliferation and apoptosis in vitro and its effect on development and progression/regression of neointimal disease, in vivo, using a rat model of neointimal hyperplasia after balloon angioplasty to carotid arteries (19).

\section{MATERIALS AND METHODS}

\section{Reagents}

Porcine aortic endothelial cells (PAEC) were cultured as described (13). We purchased human aortic (HASMC) and human coronary artery (HCSMC) SMC from Cambrex (Walkersville, MD, USA), 293 kidney embryonic cell line from American Type Culture Collection (Rockville, MD, USA), human recombinant TNF, IL-1 $\beta$ and IFN $\gamma$ from R\&D Systems (Minneapolis, MN, USA), anti-Fas IgM antibody (Ab) (clone CH-11, $\alpha$ Fas) from Kamiya Biomedical Company (Seattle, WA, USA), the control mouse IgM from Accurate Chemical \& Scientific Corporation (Westbury, NY, USA) and the NO synthase inhibitor L-NAME from Sigma (St. Louis, MO, USA).

\section{Recombinant adenoviral vectors}

We generated recombinant adenoviral vectors encoding A20

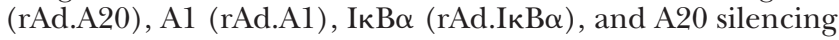
RNA (rAd.SiRA20) using the siRNA sequence previously described (20) and expanded them in 293 cells (13). Control rAd. $\beta$-galactosidase was a kind gift from Dr. R. Gerard (University of Texas SW, Dallas). The A20 expression plasmid used to generate rAd.A20 was a kind gift from Dr. V. Dixit (Genentech Inc., S. San Francisco, CA, USA). We infected SMC with rAd.A20, rAd.I $\mathrm{B} \alpha$, and rAd. $\beta$-gal at a multiplicity of infection (MOI) of 500, resulting in 95-100\% of cells expressing the transgene without toxicity.

\section{Western blot analysis (WB)}

We used the following antibodies (Abs): rabbit anti-IкB $\alpha$ IgG (Santa Cruz Biotechnology, Santa Cruz, CA, USA), mouse anti-CDKI p21 waf1 $\operatorname{IgG}_{1}$, mouse anti-CDKI p27 $7^{\text {kip } 1} \operatorname{IgG}_{1}$,

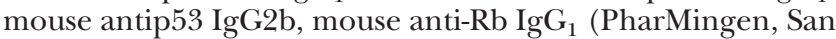
Diego, CA, USA), rat anti-hemagglutinin $\operatorname{IgG}_{1}$ monoclonal antibody (Roche Molecular Biochemicals, Indianapolis, IN,
USA), mouse anti- $\beta$-tubulin IgG2b (Chemicon International, Inc., Temecula, CA, USA), and rabbit anti-A20 polyserum generated in our lab. Secondary antibodies included peroxydase-conjugated donkey anti-rabbit $\operatorname{IgG}(\mathrm{H}+\mathrm{L})$, goat antimouse IgG and goat antirat IgG (Pierce, Rockford, IL, USA).

\section{Electrophoretic mobility shift assay (EMSA)}

We extracted nuclear proteins and analyzed them by EMSA as described (13).

\section{Flow cytometric analysis of ICAM-1 expression}

We analyzed for ICAM-1 surface expression by flow cytometry (FACScan, Becton Dickinson, Immunocytometry systems, San Jose, CA, USA) using a mouse anti-human ICAM-1 IgG (R\&D Systems, Minneapolis, MN, USA). An isotype $\operatorname{IgG}_{1}$ was used as a control (13).

\section{Northern blot analysis}

We extracted RNA using Trizol reagent (Gibco BRL, Grand Island, NY, USA). Human A20, MCP-1, and GAPDH cDNA were previously described (13).

\section{Flow cytometric analysis of apoptosis}

SMC apoptosis was induced by treatment with TNF, IFN $\gamma$, and interleukin (IL)- $1 \beta$ for $48 \mathrm{~h}$, then DNA content was analyzed on a FACScan using CELLQuest software (Becton Dickson Immunocytometric Systems, San Jose, CA, USA) as described (14).

\section{Cell cycle analysis}

Cell cycle was synchronized by culturing SMC in $0.1 \%$ FBS $\mathrm{SmBM}^{\circledR}$ for $48 \mathrm{~h}$ and gene transduction was conducted using rAd.A20, rAd.IкB $\alpha$, and rAd. $\beta$-gal. We challenged SMC $24 \mathrm{~h}$ later with $10 \% \mathrm{FBS} \mathrm{SmBM}^{\circledR}$ and analyzed cell cycle by FACS analysis of DNA content. DNA ploidy allows discrimination of cells in $\mathrm{G}_{0} / \mathrm{G}_{1}, \mathrm{~S}$, and $\mathrm{G}_{2} / \mathrm{M}$ phases of the cell cycle. In certain experiments, $5 \mathrm{mM}$ of L-NAME (Sigma) was added $6 \mathrm{~h}$ prior to challenging SMC with $10 \% \mathrm{FBS}$.

\section{Balloon angioplasty}

We performed balloon injury on adult male SD rats (300-400 g) from Harlan (Indianapolis, IN, USA) as described (19). Using a 2F embolectomy catheter (Baxter Edwards Healthcare, Irvine, CA, USA), we injured 1 to $1.5 \mathrm{~cm}$ of the left common carotid artery by intraluminal balloon inflation and passage 3 times. In the prevention studies, the injured vessel segment was filled with $30 \mu \mathrm{l}$ of vehicle or $5.10^{8}$ MOI of rAd.A20 or rAd. $\beta$-gal for $20 \mathrm{~min}$. We sacrificed the animals 14 and 28 days later and injured carotids were recovered, fixed in $10 \%$ formalin and embedded in paraffin. Additional injured carotids were recovered at 3 and 7 days and frozen for immunohistochemistry analysis. In the regression model, the injury site was re-explored 28 days later and proximal and distal control were obtained with clamps and the vessel filled with $30 \mu \mathrm{l}$ of vehicle or rAd. using a $30 \mathrm{G}$ needle. Following a $20 \mathrm{~min}$ dwell, we flushed the lumen and closed the needle hole before allowing recirculation. We sacrificed the rats at days $28+1,28+3,28+5,28+7$, and $28+14$ and vessels were recovered for morphometry and immunohistochemistry analysis. Animals were housed in the BIDMC animal care facility. All procedures and protocols were approved and 
performed in accordance with the BIDMC institutional animal care committee and published NIH guidelines.

\section{Histology and immunohistochemistry}

For morphometric analysis, we sectioned and stained paraffin embedded tissues with hematoxylin/eosin (H\&E) and measured intima /media (I/M) ratio using the NIH Image 1.62 software in a blinded fashion. Six to eight rats were used per time point and per group and six to ten serial sections, $50 \mu \mathrm{m}$ apart, were measured for each vessel. For immunohistochemistry analysis, frozen sections were stained with mouse anti-

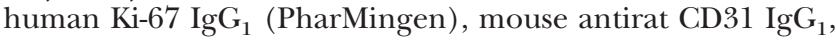
rabbit antimouse and rat inducible nitric oxide synthase (iNOS) (iNOS; M-19, Santa Cruz Biotech., Santa Cruz, CA, USA) followed by biotinylated horse antimouse-IgG or goat anti-rabbit secondary antibodies (Vector, Burlingame, CA, USA). We detected apoptosis using a tissue-specific TUNEL kit: VASOTACS (Trevigen Inc., Gaithersburg, MD, USA). Sections were scored for percentage of luminal staining for CD31 and for the number of KI67 or TUNEL positive cells per section while a semiquantitative scoring for iNOS expression in SMC was done: 0 absence of staining, 1 faint staining, 2 intense staining. Blinded observers evaluated two or more sections from 3 to 4 individual animals per time point and per group. Beta-galactosidase expression in injured vessels was detected using X-gal (Sigma, St. Louis, MO, USA).

RT-polymerase chain reaction and real-time-polymerase chain reaction

We extracted RNA from vessels or Kits using RNeasy Mini Kits (Qiagen, Valencia, CA, USA) and synthesized cDNA using Superscript First-Strand Synthesis (Invitrogen, Carlsbad, CA, USA). polymerase chain reaction (PCR) reactions were performed with the following primers: rat $\alpha$-actin: sense, $5^{\prime}$ TCATGAAGTGTGACGTTGACATCCGT-3', and antisense, 5'- CTTAGAAGCATTTGCGGTGCACGATG-3'; human A20: sense, 5'TTTGAGCAATATGCGGAAAGC-3', and antisense, 5'-AGTTGTCCCATTCGTCATTCC-3'; human iNOS: sense: 5'-GGCCTCGCTCTGGAAAGA-3' , and antisense 5' ${ }^{\prime}$-TCCATGCAGACAACCTT-3' . RNA was also extracted from HASMC to check for human A1 mRNA levels using previously described primers (21). PCR reactions were optimized for each primer pair. We performed PCR over a range of cycles (15-40) to ensure amplification in the linear range and used equal starting amounts from each sample. In addition, real-time (quantitative) PCR reactions were performed using primers from Applied Biosystems assays-on-demand to quantify human iNOS mRNA. Amplification of ribosomal 18s was used to correct for loading.

\section{Statistical analysis}

Quantitative data was expressed as mean \pm SE. If SD were equal within the populations, an unpaired 2-tailed Student's $t$ test was used to compare treatment groups. If SD values differed significantly, a nonparametric Mann-Whitney test was used. A value of $P<0.05$ was considered statistically significant.

\section{RESULTS}

\section{A20 inhibits NF-кB activation in SMC upstream of $\mathbf{I} \kappa \mathbf{B} \alpha$ degradation}

We induced A20 mRNA (Northern blot) and protein (WB) expression in SMC $1 \mathrm{~h}$ and $6 \mathrm{~h}$ after stimulation with $100 \mathrm{U} / \mathrm{ml}$ of tumor necrosis factor $\alpha$ (TNF), respectively (Fig. 1A). This result demonstrates that A20 is part of the physiological response of SMC to inflammation. We next tested whether A20 manifests its NF-кB inhibitory function in SMC. We stimulated SMC with $100 \mathrm{U} / \mathrm{ml}$ of TNF and nuclear and cytoplasmic extracts were recovered from nontransduced (NT), (rAd.) rAd.A20, and rAd. $\beta$-gal -transduced SMC at 0, 15, and $120 \mathrm{~min}$. Overexpression of A20 in SMC inhibited IкB $\alpha$ degradation (WB) after TNF stimulation (Fig. 1B). SMC transduced with rAd.SiRA20 demonstrated lasting I $\mathrm{B} \alpha$ degradation (120 $\mathrm{min}$ ) indicating, as in knock-out
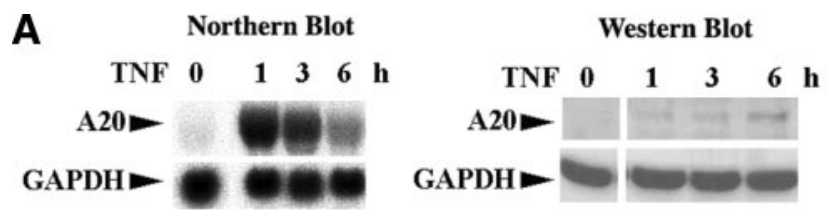

B

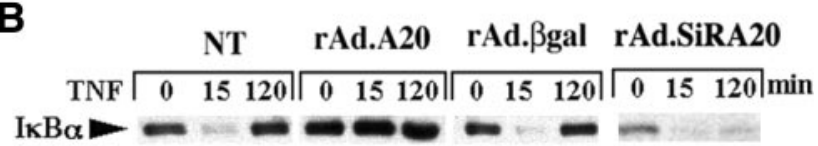

C

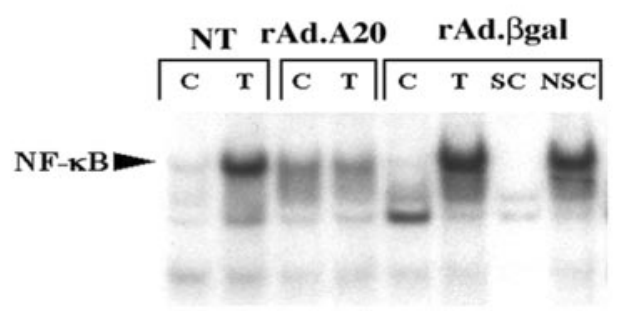

D
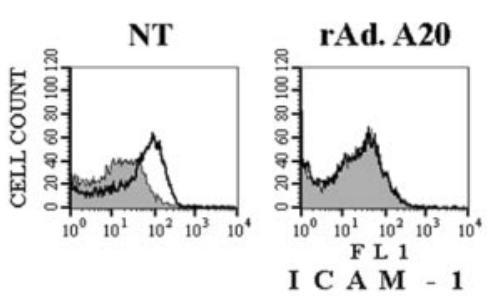

rAd. $\beta$-gal

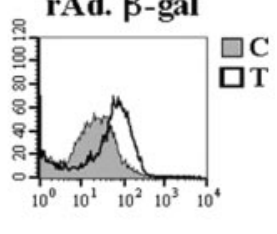

$\mathbf{E}$

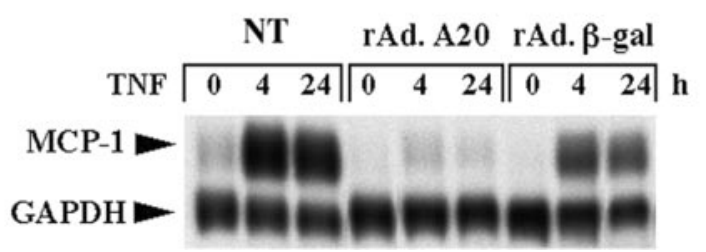

Figure 1. Northern blot analysis and Western blot analysis of A20 mRNA and protein after treatment with $\mathrm{TNF}(A)$. Overexpression of A20 in SMC inhibits I $\mathrm{I} B \alpha$ degradation after TNF stimulation as shown by Western blot analysis, whereas knockdown of A20 SiRNA leads to prolonged I $\mathrm{BB} \alpha$ degradation $(B)$. Similarly, A20 expression in SMC inhibits $\mathrm{NF}-\kappa \mathrm{B}$ nuclear translocation $2 \mathrm{~h}$ after $\mathrm{TNF}(\mathrm{TNF}=\mathrm{T})$. Specific competitor (SC); nonspecific competitor (NSC); control $(C)$ are nuclear extracts recovered prior to addition of TNF $(C)$. A20 expression in SMC inhibits TNF-mediated ICAM-1 upregulation (FACS analysis; empty histogram). Nontreated SMC control (filled histogram) $(D)$ and TNF-mediated MCP-1 up-regulation (Northern blot analysis) (E). Results shown are representative of 3 independent experiments. 
A20 mice, prolonged NF-кB activation (22) (Fig. $1 B$ ). We also showed by EMSA that there was no TNF inducible binding for the NF-кB consensus oligonucleotides in A20-expressing SMC as opposed to high binding in NT or rAd. $\beta$-gal-transduced SMC (Fig. 1C). As a corollary, A20 expression in SMC inhibited TNFmediated up-regulation of the proinflammatory/ proatherogenic NF-кB-dependent genes ICAM-1 and MCP-1 as demonstrated by FACS and Northern blot analysis, respectively (Fig. $1 D, E$ ).

\section{Overexpression of A20 inhibits SMC proliferation through blockade of $\mathbf{R b}$ hyperphosphorylation and an increased expression of CDKI p27 ${ }^{\mathrm{kip} 1}$, p21 ${ }^{\text {waf1 }}$, and p53}

Having established that A20 inhibits NF-кB activation, we questioned whether such inhibition would affect SMC proliferation. We synchronized the cell cycle of SMC by culturing them in medium containing $0.1 \%$ FBS, induced proliferation by adding $10 \%$ FBS, and analyzed DNA content 24, 48, and $72 \mathrm{~h}$ later. We showed no progression through the cell cycle in A20expressing SMC. The percentage of SMC in the $\mathrm{S}+\mathrm{G}_{2} / \mathrm{M}$ phases of the cell cycle before and after addition of FBS was comparable reaching $12 \pm 1 \%$ and $16 \pm 2 \%$, respectively ( $n=4$; Fig. $2 A$ ). Overexpression of $\mathrm{I} \kappa \mathrm{B} \alpha$, used as a positive control for NF-кB inhibition, equally prevented cell cycle progression (Fig. 2A), suggesting that A20-mediated inhibition of SMC proliferation could be related to its inhibition of NF-кB. A20and $\mathrm{I} \kappa \mathrm{B} \alpha$-mediated inhibition of cell cycle progression was maintained up to $72 \mathrm{~h}$ (data not shown), confirming that this effect was not merely a delay to entry. In contrast, NT and rAd. $\beta$-gal transduced SMC progressed through the cell cycle after supplementation with FBS. The percentage of NT and rAd. $\beta$-gal transduced SMC in the $\mathrm{S}+\mathrm{G}_{2} / \mathrm{M}$ phases of the cell cycle increased from $12 \pm 1 \%$ to $43 \pm 4 \%$ and $16 \pm 2 \%$ to $34 \pm 2 \%$, respectively, after $10 \%$ FBS $(n=4$; Fig. $2 A)$. SMC transduced with rAd. $\beta$-gal showed a delayed entry into cell cycle $(48 \mathrm{~h})$ compared to NT SMC $(24 \mathrm{~h})$, which may be attributable to adenoviral toxicity (Fig. 2A). To dissect the molecular basis of A20-mediated inhibition of cell cycling in SMC, we tested whether A20 expression modifies the phosphorylation of retinoblastoma $(\mathrm{Rb})$. Hyperphosphosphorylated $\mathrm{Rb}$ (ppRB) undergoes a conformational change and releases E2F, a key transcription factor involved in driving the cell cycle. We showed that most of the $\mathrm{Rb}$ protein was in its hypophosphorylated state at the end of the starvation period (Fig. 2B). Hyperphosphorylated $\mathrm{Rb}$ was detected $36 \mathrm{~h}$ after adding 10\% FBS in NT and rAd. $\beta$-gal transduced SMC (Fig. 2B). Overexpression of either $\mathrm{A} 20$ or $\mathrm{I} \kappa \mathrm{B} \alpha$ in $\mathrm{SMC}$ inhibited Rb phosphorylation. Sequential activation of cyclins $\mathrm{D}$ and $\mathrm{E}$ and their cyclin-dependent kinases (CDK) drives phosphorylation of $\mathrm{Rb}$ during the $\mathrm{G}_{1}$ phase of the cell cycle. These cyclin/CDK complexes are under the control of CDK inhibitors (CDKI) (23). We evaluated whether A20
A
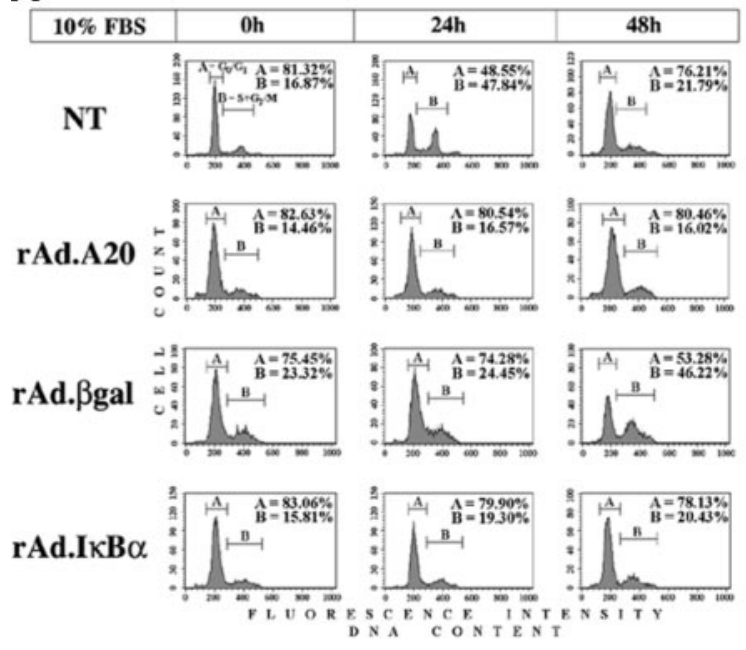

B

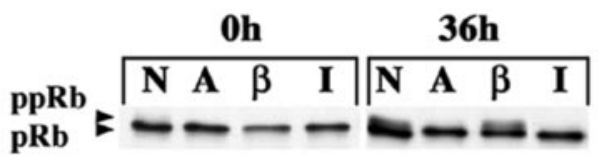

C
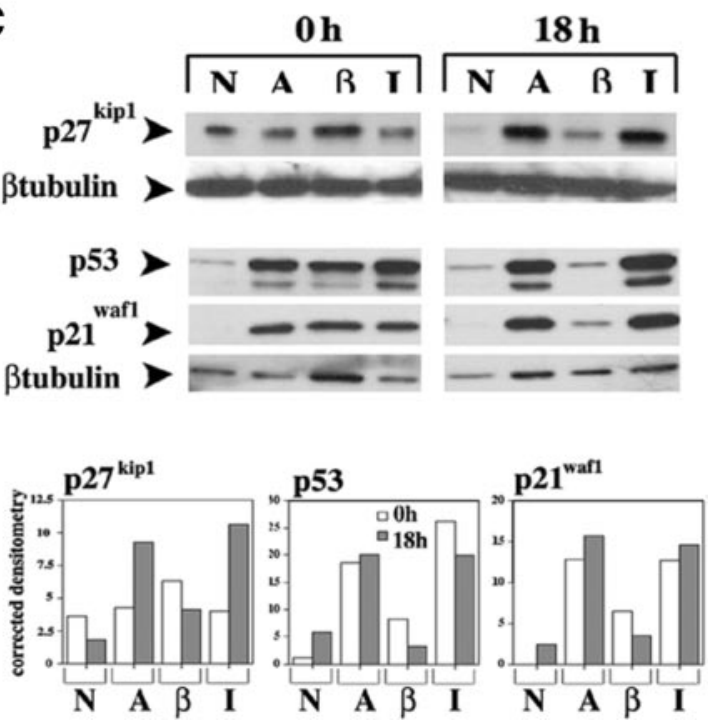

Figure 2. Cell cycle after addition of 10\% FBS (FACS). Overexpression of A20 and ІкB $\alpha$ inhibits SMC progression through the cell cycle. Histogram areas labeled A, B represent cells in the $\mathrm{G}_{0} / \mathrm{G}_{1}$ and $\mathrm{S}+\mathrm{G}_{2} / \mathrm{M}$ of the cell cycle $(A)$. Western blot of $\mathrm{Rb}$ demonstrates phosphorylation of $\mathrm{RB}$ $(\mathrm{ppRb})$ in NT $(\mathrm{N})$ and rAd. $\beta$-gal $(\mathrm{B})$ transduced SMC but not in rAd.A20 (A) and rAd.Ikb $\alpha$ (I) transduced SMC after addition of $10 \%$ FBS $(B)$. Expression of p2 $7^{\text {kip } 1}$, p21 $1^{\text {wafl } 1}$, and p53 is increased in A20- and IкB $\alpha$-expressing SMC before and $18 \mathrm{~h}$ after addition of $10 \%$ FBS (Western blot analysis). Btubulin serves as a control for equal loading. Relative protein expression is determined by densitometry and corrected by the intensity of $\beta$ tubulin bands $(C)$. Results shown correspond to one representative experiment of 3 performed.

alters the expression of the CDKI p21 $1^{\text {waf1 }}$ and $\mathrm{p} 27^{\mathrm{kip} 1}$. Expression of p27 $7^{\text {kip } 1}$ was high at the end of SMC starvation with a tendency to higher levels in rAd. $\beta$-gal transduced SMC. CDKI p27 $7^{\text {kip }}$ levels decreased substantially $18 \mathrm{~h}$ after addition of FBS in NT and rAd. $\beta$-gal 
transduced SMC. In contrast, p27 $7^{\mathrm{kip} 1}$ protein levels increased by 2- to 3-fold in $\mathrm{rAd}$.I $\mathrm{KB} \alpha$ and rAd.A20 transduced SMC (Fig. 2C). Protein levels of $\mathrm{p} 21^{\text {wafl }}$ were low in NT SMC at the end of the starvation period and increased very moderately $18 \mathrm{~h}$ after addition of $10 \%$ FBS. In contrast, high levels of $\mathrm{p} 21^{\text {wafl }}$ were detected in all rAd. transduced SMC at the end of starvation, albeit these levels were twice as high in rAd.I $\mathrm{B} \alpha$ and rAd.A20 transduced SMC compared to those transduced with rAd. $\beta$-gal. CDKIp21 ${ }^{\text {wafl }}$ levels further increased in $\mathrm{A} 20$ - and IКB $\alpha$-expressing SMC $18 \mathrm{~h}$ after addition of FBS, whereas they significantly decreased in rAd. $\beta$-gal transduced SMC (Fig. 2C). Expression of $\mathrm{p} 21^{\text {wafl }}$ is regulated in part by the tumor suppressor gene p53 (24). We demonstrate that expression of p53 paralleled that of p21 ${ }^{\text {wafl }}$ with sustained up-regulation of p53 expression noted in A20- and IкB $\alpha$-expressing SMC before and after addition of $10 \%$ FBS (Fig. 2C). The limited and moderate increase of $\mathrm{p} 53 / \mathrm{p} 21^{\text {wafl }}$ and $\mathrm{p} 27^{\mathrm{kip} 1}$ that was detected in $\mathrm{rAd} . \beta$-gal transduced SMC prior to addition of FBS decreased thereafter and likely accounts for their delayed entry in the cell cycle. These data suggest that A20 blocks cell cycle progression by increasing p53 and its target gene p21 $1^{\text {watl }}$ as well as p2 $7^{\text {kip }}$.

\section{Overexpression of A20 sensitizes SMC to cytokine and Fas-mediated apoptosis}

A20 is an antiapoptotic protein in most cells including EC but its effect on SMC apoptosis is not known. We recovered NT, rAd.A20, rAd.IkB $\alpha$, and rAd. $\beta$-gal transduced HASMC $48 \mathrm{~h}$ after treatment with $400 \mathrm{U} / \mathrm{ml}$ of $\mathrm{TNF}, 400 \mathrm{U} / \mathrm{ml}$ of IFN $\gamma$ and $100 \mathrm{U} / \mathrm{ml}$ of IL- $1 \beta / \mathrm{ml}$ and evaluated apoptosis by DNA content analysis (14). The percentage of apoptotic cells $48 \mathrm{~h}$ after cytokine treatment was negligible in NT and rAd. $\beta$-gal-transduced SMC $(<6 \%$; Fig. $3 A)$ while it increased significantly in A20-expressing SMC from $4.0 \pm 0.5 \%$ to $36.6 \pm 4.2 \%$ $48 \mathrm{~h}$ after cytokine treatment $(P<0.0001 ; n=5)$. Despite equivalent NF-кB inhibition, SMC expressing IкB $\alpha$ demonstrated less apoptosis than A20-expressing cells. The percentage of apoptosis in I $\mathrm{B} \alpha$-expressing $\mathrm{SMC}$ increased from $3.0 \pm 1.0 \%$ to $13.0 \pm 3.0 \%(n=5$; $P=0.001$; Fig. $3 A$ ).

This unexpected proapoptotic effect of A20 in SMC extends to the cross-linking of the death receptor Fas. The percentage of apoptotic cells after treatment with $1 \mu \mathrm{g} / \mathrm{ml}$ of $\alpha$ Fas was negligible in NT and rAd. $\beta$-galtransduced SMC $(<2.2 \%$; Fig. $3 B)$ while a high rate of apoptosis was detected in A20-expressing SMC, increasing from $2.5 \pm 0.5 \%$ to $26.0 \pm 8.0 \%$ after addition of $\alpha$ Fas $(n=3 ; P<0.0001 ;$ Fig. $3 B)$. Apoptosis was not detected after treatment of SMC with the control IgM Ab. Similar results were obtained in aortic or coronary artery SMC. Both were used in later experiments and referred to as SMC. These results demonstrate for the first time a proapoptotic function for A20 in SMC. A20-mediated sensitization of SMC to apoptosis is consistently greater than that seen in ІкB $\alpha$-expressing
A

\begin{tabular}{|c|c|c|}
\hline TNF $(400 \mathrm{U} / \mathrm{ml})$ & - & + \\
\hline $\mathrm{IFN}-\gamma(400 \mathrm{U} / \mathrm{ml})$ & - & + \\
\hline $\mathrm{IL}-1 \beta(100 \mathrm{U} / \mathrm{ml})$ & - & + \\
\hline
\end{tabular}
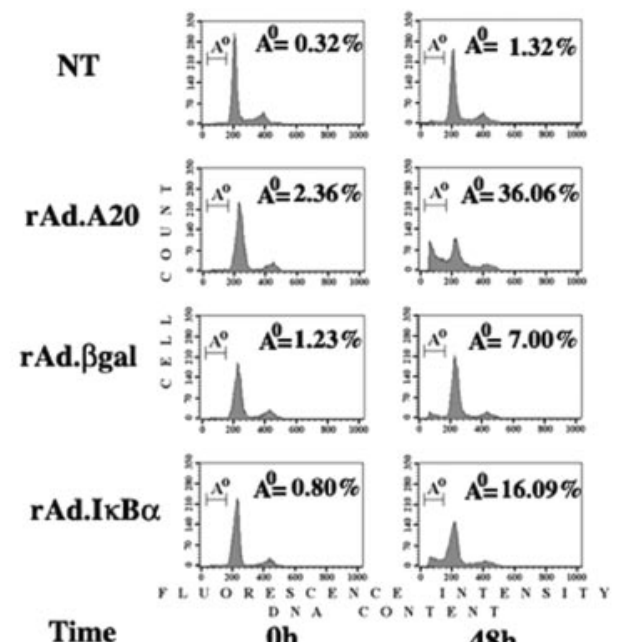

Time $\quad 0$ h 48 h

B

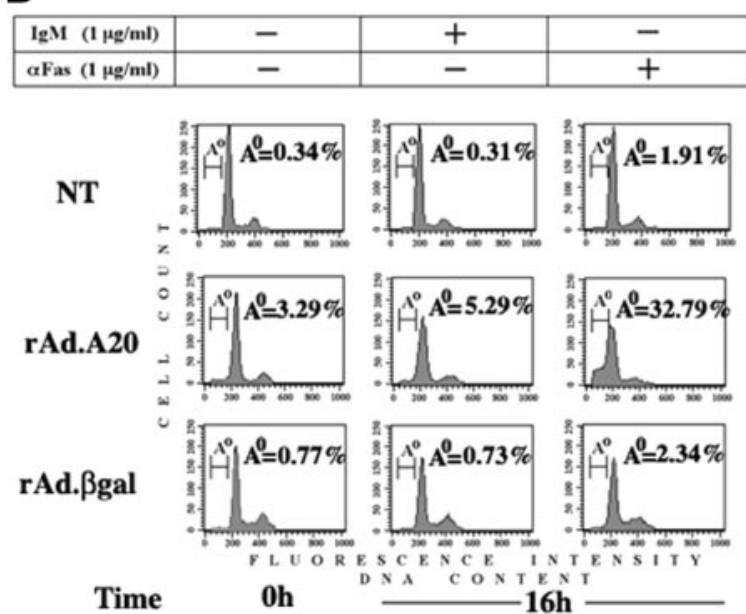

Figure 3. SMC apoptosis was evaluated by DNA content analysis after cytokine and $\alpha$ Fas treatment. The hypodiploid region $(<2 \mathrm{~N})$, designated $\mathrm{A}^{0}$, represents cells undergoing apoptosis. Overexpression of A20 in SMC sensitizes SMC to cytokine $(A)$ and $\alpha$ Fas-mediated apoptosis. SMC stimulated with IgM are used as controls $(B)$. Data shown are from one experiment that is representative of 5 (cytokines) and 3 $(\alpha$ Fas) independent experiments.

SMC, suggesting that this novel function of A20 is not likely to be solely related to inhibition of NF-кB.

Cotransduction of SMC with the antiapoptotic, NF-кB-dependent, bcl gene A1 does not revert the proapoptotic effect of $A 20$ while rescuing IKB $\alpha$ expressing SMC from apoptosis

To determine the molecular basis of the proapoptotic effect of A20 in SMC, we questioned whether overexpression of A20 modified the ratio of antiapoptotic (A1, Bcl- $\mathrm{x}_{\mathrm{L}}$ and IAP-1) and proapoptotic (Bcl- $\mathrm{x}_{\mathrm{S}}$ and $\left.\mathrm{Bax}\right)$ proteins in SMC. Messenger RNA levels for the anti- 
apoptotic $b c l$ family member A1 were determined by semiquantitative RT-PCR in NT and rAd.A20, rAd.IкB $\alpha$ and rAd. $\beta$-gal transduced SMC after addition of cytokines. Low levels of A1 mRNA were detected prior to adding cytokines and were up-regulated by 1.5- to 1.8 -fold $3 \mathrm{~h}$ after in NT and rAd. $\beta$-gal transduced SMC. Expression of $\mathrm{A} 20$ and $\mathrm{I} \kappa \mathrm{B} \alpha$ inhibited cytokine-mediated up-regulation of A1mRNA (Fig. 4A), consistent with studies showing that $\mathrm{A} 1$ is dependent on NF- $\mathrm{B}$ for its induction (21). Comparable protein levels of Bcl- $\mathrm{x}_{\mathrm{L}}$, IAP-1, Bcl- $\mathrm{x}_{\mathrm{S}}$ and Bax were detected (WB) in all groups before and after treatment with cytokines (data not shown).

To evaluate whether altered A1 induction was responsible for increased SMC apoptosis in A20- and IкB $\alpha$ expressing SMC, NT SMC and SMC expressing A20, ІкB $\alpha$ and $\beta$-gal were cotransduced with rAd.A1 prior to triggering apoptosis. SMC expressing A1 alone or in combination with $\beta$-gal demonstrated low basal rate of apoptosis, which was not modified by cytokine treatment (Fig. $4 B$ ). SMC coexpressing A20 and A1 demonstrated higher basal rate of apoptosis that was increased by cytokines, reaching similar percentages to those reached in SMC expressing A20 alone (34\%, Fig. $4 B, n=3$ ). In contrast, coexpression of $\mathrm{A} 1$ and $\mathrm{I} \kappa \mathrm{B} \alpha$ rescued SMC from cytokine-mediated apoptosis $(<4 \%$ apoptotic SMC after treatment with cytokines; Fig. $4 B$ ). We confirmed coexpression of $\mathrm{A} 1$ and $\mathrm{A} 20$ or $\mathrm{A} 1$ and $\mathrm{I} \kappa \mathrm{B} \alpha$ by WB (Fig. $4 B$ ). These findings provide additional proof that the proapoptotic function of A20 in SMC is likely independent from its inhibitory effect on NF-kB and NF-кB-dependent antiapoptotic proteins such as $\mathrm{A} 1$.

\section{The proapoptotic effect of A20 relates to NO- dependent DNA fragmentation}

We confirmed that cell death in SMC overexpressing A20 was related to apoptosis and not necrosis by showing a significant number of TUNEL positive apoptotic nuclei in A20-expressing SMC after treatment with cytokines (Fig. 5A) whereas none were detected in rAd.ß-gal transduced SMC (data not shown). Despite confirmation of apoptotic cell death, expression of A20 in SMC did not alter caspase 8 or 3 activity nor disrupted the mitochondrial transmembrane potential after cytokine treatment (data not shown), suggesting that the proapoptotic effect of A20 in SMC was the result of direct DNA damage. $\mathrm{NO}$ has been shown to cause direct damage to DNA in SMC (25). We probed for $\mathrm{NO}$ involvement in A20-mediated sensitization of SMC to apoptosis. Pretreatment of rAd.A20 transduced SMC with the NO synthase inhibitor L-NAME for $6 \mathrm{~h}$ prior to adding cytokines led to a dose-dependent reversal of the proapoptotic effect of A20 (Fig. $5 \mathrm{~B}$ ). The rate of apoptosis increased from $4.5 \pm 0.8 \%$ to $16.0 \pm$ $1.3 \%(n=4 ; P<0.0001)$ after addition of cytokines. Preincubation of SMC with $2.5 \mathrm{mM}$ and $5.0 \mathrm{mM}$ of L-NAME prior to adding cytokines decreased SMC apoptosis to $9.4 \pm 0.9 \%(n=4 ; P<0.0003)$ and $5.2 \pm$ $0.2 \%(n=3 ; P<0.0001)$, respectively (Fig. $5 B)$. These results demonstrate that the novel proapoptotic func-
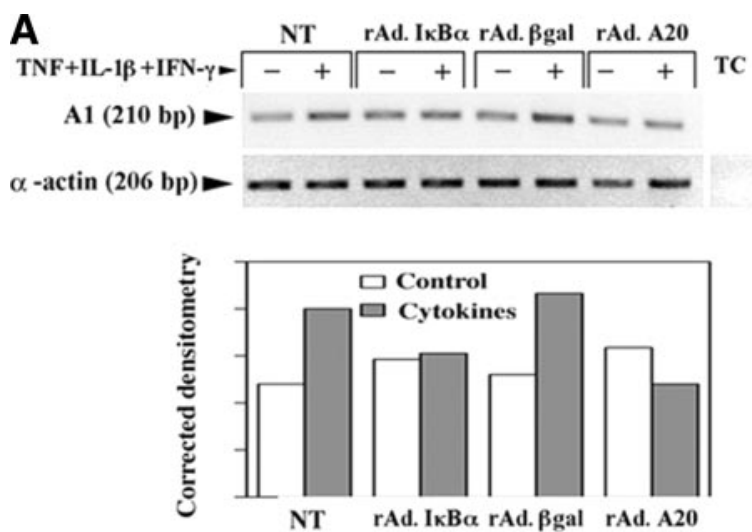

B

\begin{tabular}{|c|c|c|}
\hline TNF+IL $-1 \beta+$ IFN- $\gamma$ & - & + \\
\hline rAd. A1 & + & + \\
\hline
\end{tabular}
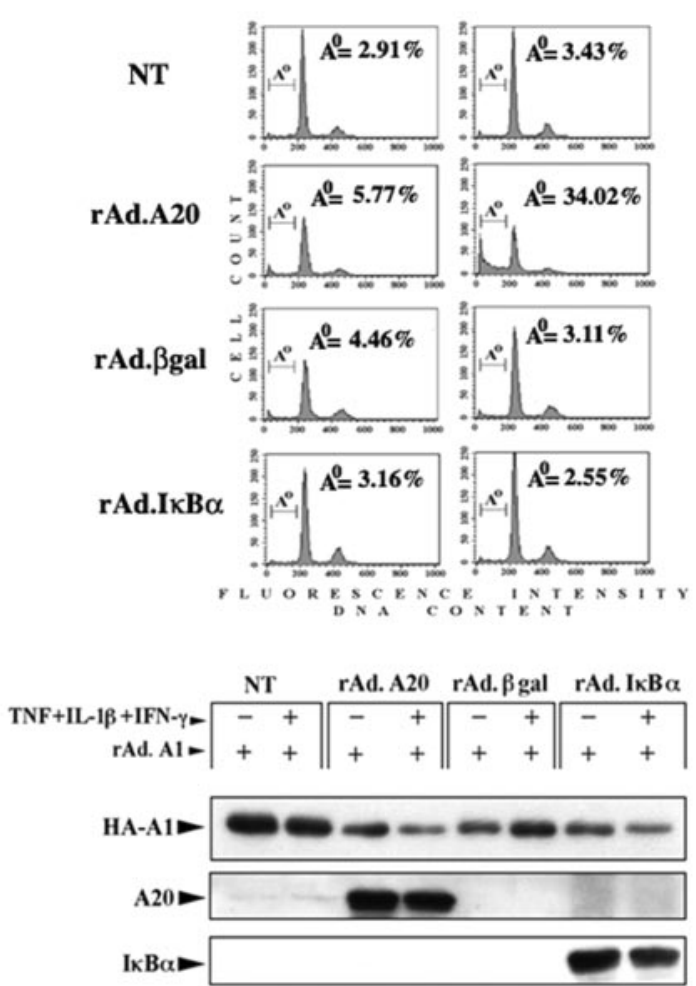

Figure 4. Semiquantitative RT-PCR demonstrates increased A1 mRNA levels NT and rAd.ßgal transduced SMC after treatment with cytokines whereas no induction is detected in $\mathrm{A} 20$ - and IкB $\alpha$-expressing SMC. Corrected densitometry allowed determination of relative A1 mRNA levels $(A)$. Cotransduction of SMC with rAd.A1 reverts the proapoptotic effect of I $\mathrm{B} \alpha$ but not that of A20 as determined by FACS analysis of DNA content $(B)$. Western blot analysis is done to check for coexpression of the transgenes. Results shown are representative of 3 independent experiments.

tion of A20 in SMC is NO dependent. Consequently, induction of iNOS mRNA after stimulation with cytokines was 2-fold higher in A20-expressing SMC compared to controls (Fig. 5C). There was no or very little iNOS mRNA detectable by real-time PCR prior to the addition of cytokines. A significant increase in iNOS mRNA was noted in A20-expressing SMC $18 \mathrm{~h}$ after treatment with cytokines reaching a $4.07 \pm 0.8$ (mRNA 
A

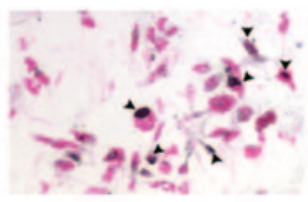

C

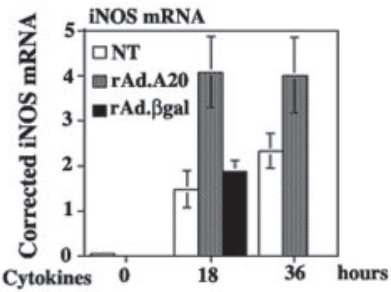

$\mathbf{E}$
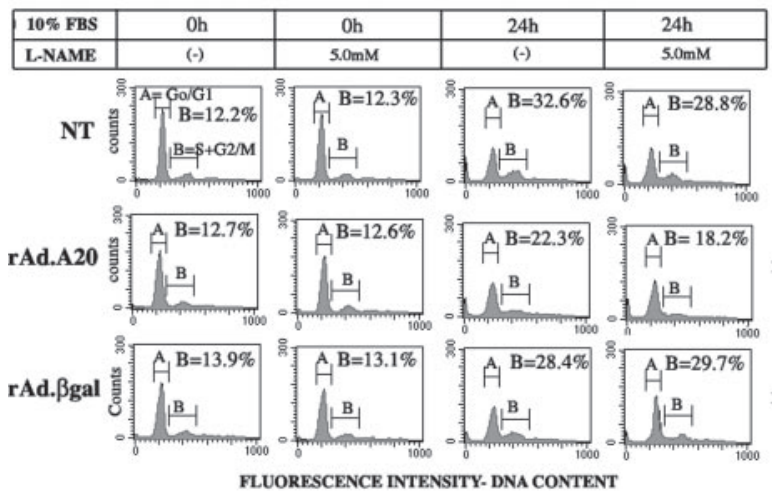

D

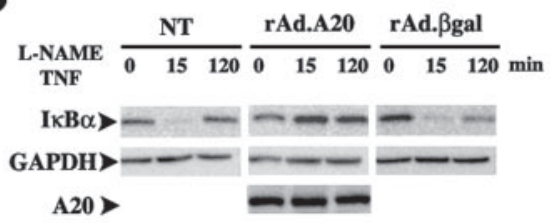

$\mathbf{F}$

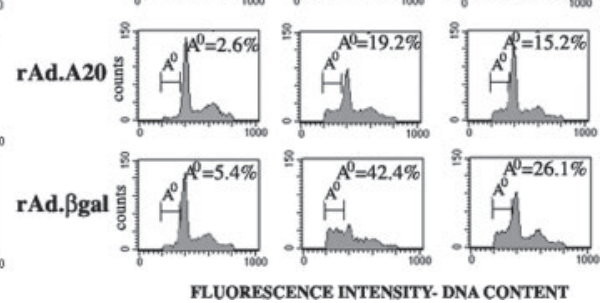

Figure 5. TUNEL positive SMC are detected $48 \mathrm{~h}$ after cytokine treatment in A20-expressing SMC $(A)$. Data shown are representative of 3 independent experiments. Preincubation with L-NAME protects A20-expressing SMC from cytokinemediated apoptosis (FACS analysis of DNA content), Data shown is representative of 3 independent experiments $(B)$. iNOS mRNA is significantly higher in A20-expressing SMC compared to controls, $18 \mathrm{~h}$ after cytokine treatment as determined by real-time PCR $(C)$. Preincubation of SMC with L-NAME does not modify the inhibitory effect of A20 on IkB $\alpha$ degradation $(D)$ or its antiproliferative effect $(E)$. Similarly, preincubation with L-NAME does not affect the antiapoptotic effect of A20 in EC after CHX/TNF (E). Experiments shown are representative of 3 (SMC) and 4 (EC) independent experiments.

corrected with median computed tomography and 18s). Cytokine-mediated increase of iNOS mRNA was significantly lower in NT $(1.47 \pm 0.41 ; P=0.02)$ and rAd. Bgal transduced SMC $(1.86 \pm 0.26 ; P=0.03 ; n=2$ experiments performed in quadruplicate). High iNOS mRNA levels in A20-expressing SMC persisted up to $36 \mathrm{~h}$ after addition of cytokines $(4 \pm 0.83)$. The molecular basis for increased iNOS transcription in A20-expressing SMC after treatment with cytokines is under investigation.

We then sought to clarify the potential implication of $\mathrm{NO}$ in the anti-inflammatory and antiproliferative functions of A20 in SMC. Pretreatment of A20-expressing SMC with L-NAME ( $5 \mathrm{mM})$ did not affect its inhibitory effect on IкB $\alpha$ degradation, as shown by WB (Fig. $5 D$, $n=3$ ). Similarly, pretreatment with L-NAME did not alter the antiproliferative effect of A20 in SMC. A20expressing SMC did not significantly progress through the cell cycle $24 \mathrm{~h}$ after addition of $10 \% \mathrm{FBS}$, whether pretreated or not with L-NAME. A20-expressing SMC in the $\mathrm{S}+\mathrm{G}_{2} / \mathrm{M}$ phases of the cell cycle increased from $12-18 \%$ prior to addition of FBS to $21.7 \pm 0.8 \%$ in untreated SMC and $19.7 \pm 1 \%$ in L-NAME pretreated SMC ( $P=\mathrm{NS}, n=3$ experiments performed in duplicate, Fig. $5 E$ ). In contrast, the percentage of SMC in the
$\mathrm{S}+\mathrm{G}_{2} / \mathrm{M}$ phases of the cell cycle in NT and rAd.ßgal transduced SMC doubled $24 \mathrm{~h}$ after addition of $10 \%$ FBS reaching $30.2 \pm 0.8 \%$ and $27.8 \pm 0.7 \%$ in untreated SMC and $28 \pm 0.6 \%$ and $26 \pm 0.8 \%$ in L-NAME pretreated SMC, respectively. There was even a tendency to less cell proliferation in L-NAME pretreated SMC. These data strongly argue that the antiproliferative effect of A20 in SMC is NO independent.

Similarly, the antiapoptotic effect of A20 in EC was not altered by NO blockade. The percentage of apoptotic EC reached $44.5 \pm 1.6 \%$ and $46.5 \pm 2.4 \%$ in NT and rAd. $\beta$-gal transduced EC whereas it was half that number in A20 expressing EC $(28.1 \pm 2.7 \%) 9 \mathrm{~h}$ after treatment with CHX/TNF $(n=4 ; P<0.01 ;$ Fig. $5 E)(14)$. The beneficial effect of A20 was not abrogated when EC were pretreated with L-NAME for $4-6 \mathrm{~h}$ (the rate of apoptosis was even lower, reaching $21.0 \pm 3.4 \%$ ).

\section{A20 expression inhibits neointima formation by inhibiting SMC proliferation in vivo and supporting regeneration of the endothelium}

To test how these newly described functions of A20 in SMC translate in vivo, we tested the effects of A20 
expression on vascular remodeling after balloon angioplasty injury to rat carotid arteries. We injured left common carotid arteries of adult male Sprague Dawley rats and treated the vessels with normal saline, rAd.A20 or control rAd. $\beta$-gal as detailed in the methods. We found that $5 \times 10^{8}$ pfu achieved high levels of expression of the transgene in $30-40 \%$ of medial SMC at day 3 with a decrease by day 14, without any toxicity (Fig. $\mathbf{6 B})$. We confirmed vascular A20 expression by RT-PCR that showed expression of the human A20 transgene in rAd.A20 transduced vessels while low levels of endogenous rat A20 were detected in NT and rAd. $\beta$-gal transduced carotids (Fig. 6B). Endogenous A20 was not detected in vessels overexpressing the human A20 transgene, consistent with the fact that A20 expression is NF-кB dependent, hence inhibited by the A20 transgene (26). We observed significant neointimal hyperplasia in NT and rAd. $\beta$-gal transduced carotids with intima/media $(\mathrm{I} / \mathrm{M})$ ratios reaching $0.79 \pm 0.15(n=6$; $n=$ refers to the number of animals/group) and $0.84 \pm$ $0.13(n=6)$, respectively. A20 expression significantly inhibited neointima formation with an $\mathrm{I} / \mathrm{M}$ ratio of $0.30 \pm 0.04(n=7 ; P=0.022$ vs. NT and $P=0.001$ vs. rAd. $\beta$-gal) (Fig. $6 A$ ). This protective effect was maintained up to 28 days with $\mathrm{I} / \mathrm{M}$ ratios of $0.79 \pm 0.11$ $(n=6)$ and $0.70 \pm 0.17(n=6)$ in NT and rAd. $\beta$-gal transduced arteries while that of A20 expressing arteries remained at $0.31 \pm 0.09(n=8 ; P=0.004 v s$. NT and $P=0.044$ vs. rAd. $\beta$-gal; Fig. $6 A)$.

Consistent with the antiproliferative function of A20 in SMC, in vitro, KI67 was significantly diminished in A20 expressing vessels. (Fig. 6C). The number of KI67 positive cells was $91.2 \pm 22.0$ per section $(n=3$; "n" refers to the number of vessels; 2 or more sections were analyzed per vessel) in rAd. $\beta$-gal transduced vessels compared to $13.5 \pm 7.2(n=3 ; P=0.03)$ in A20 expressing vessels. KI67 immunoreactivity was detected in both medial and neointimal SMC in rAd. $\beta$-gal transduced carotids whereas its expression was limited to the few neointimal SMC present in A20 expressing carotids. No KI67 was detected in control noninjured vessels. We used CD31 immunoreactivity, a specific marker of EC, to probe for re-endothelialization of the injured carotids. Injured vessels did not express luminal CD31 3 days postinjury, confirming appropriate de-endothelialization of all vessels. At 7 days postinjury, we detected CD31 positive cells on $16.5 \pm 5.5 \%(n=4)$ of the lumen in rAd. $\beta$-gal transduced vessels in contrast to $57.0 \pm$ 9.7\% $(n=3 ; P=0.0008)$ in rAd.A20 transduced vessels (Fig. 6C). Low levels of SMC apoptosis were detected by TUNEL 3 and 7 days following balloon angioplasty and were comparable in NT, rAd.A20, and rAd.Bgal transduced vessels despite higher levels of iNOS mRNA in A20-expressing SMC, as seen in vitro (Fig. $6 B, C$ ). This later result indicates that the proapoptotic effect of A20 demonstrated in SMC cultures was either not relevant in vivo when the A20 transgene was expressed in medial SMC or that apoptotic SMC were rapidly cleared.

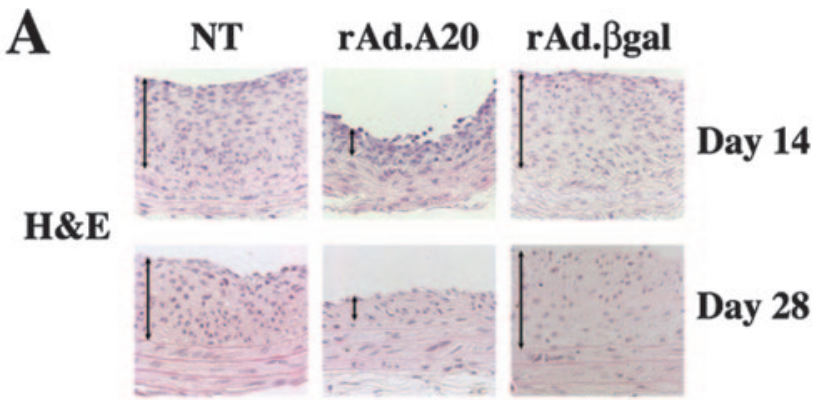

B
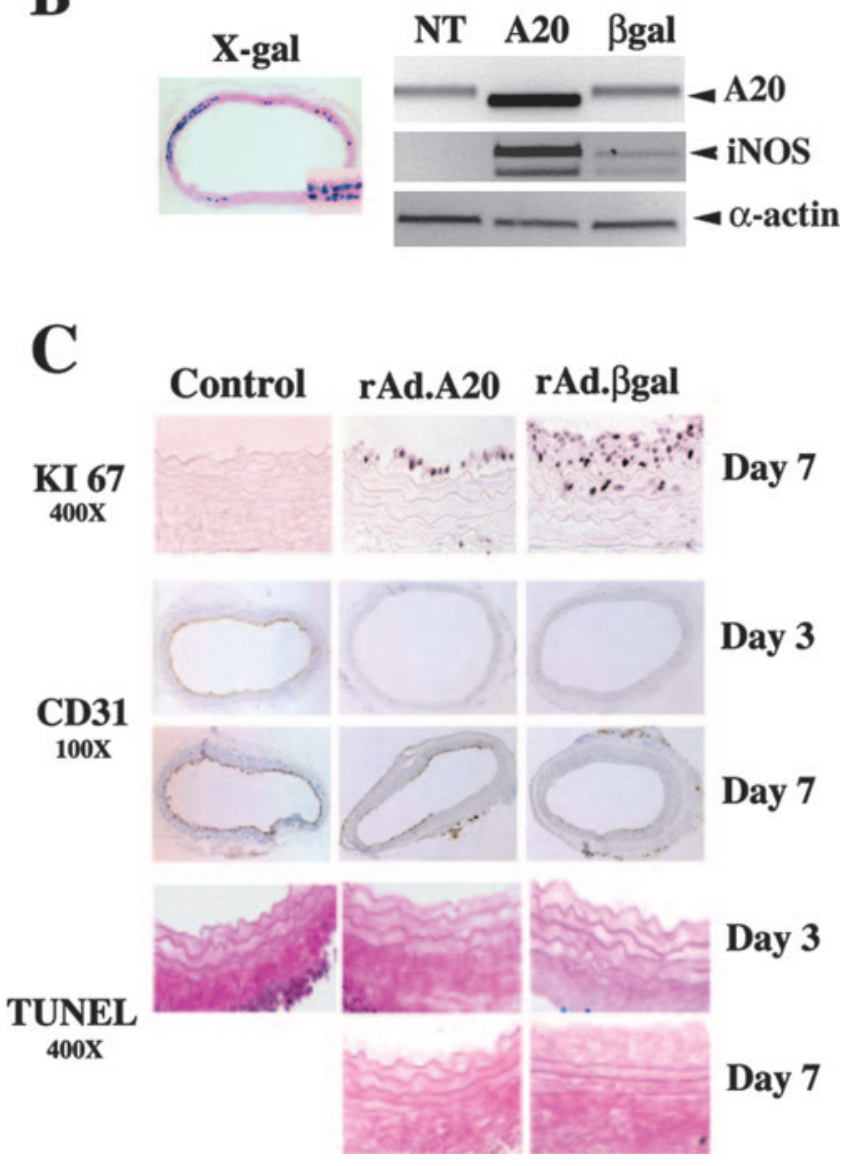

Figure 6. Evaluation of $\mathrm{I} / \mathrm{M}$ ratio on $\mathrm{H} \& \mathrm{E}-\mathrm{stained}$ rat carotid arteries sections 14 and 28 days after balloon angioplasty demonstrates significant neointimal lesions in NT and rAd. $\beta$-gal transduced vessels that are significantly inhibited in A20 expressing vessels. Arrows define the neointima $(A)$. Transgene expression is confirmed by X-gal staining ( $100 \times$; inset $400 \times)$ and semiquantitative RT-PCR of $\beta$-gal and A20 transduced vessels. INOS mRNA, evaluated by semiquantitative RT-PCR is also shown $(B)$. Immunohistochemistry analysis of carotid arteries sections 7 days after balloon injury demonstrates less KI67 staining (dark purple spots) in A20 expressing vessels compared to rAd. $\beta$-gal transduced vessels $(C)$. Absence of CD31 immunostaining 3 days postinjury confirms equal de-endothelialization in rAd.A20 and rAd. $\beta$-gal transduced vessel with recovery of CD31 luminal staining (rust color) 7 days after angioplasty in A20 as opposed to $\beta$-gal expressing vessels $(C)$. No or little apoptosis is detected by TUNEL at days 3 and 7 following balloon injury. Few positive (blue) apoptotic cells are detected in the adventitia. Uninjured vessels were used as control (C). Representative sections are shown $(100 \times$ and $400 \times)$. 
The proapoptotic function of A20 appears restricted, in vivo, to neointimal SMC and accounts for regression of established neointimal hyperplasia

We next evaluated the impact of A20 expression in neointimal SMC on already established neointimal lesions. We injured the left common carotid artery and allowed neointimal hyperplasia to develop for 28 days. The $\mathrm{I} / \mathrm{M}$ ratio at day 28 was at $0.91 \pm 0.1 \quad(n=6)$. Injured vessels were then revisited and infused with either normal saline or $5 \times 10^{8}$ pfu of rAd.A20 or rAd. $\beta$-gal. Rats were killed 14 days later and injured carotids retrieved for morphometry and immunohistochemistry analysis. The $\mathrm{I} / \mathrm{M}$ ratio at day $28+14$ in saline and rAd. $\beta$-gal transduced carotids reached $1.06 \pm 0.10(n=8)$ and $1.04 \pm 0.16(n=6)$, respectively, and was not different from the $\mathrm{I} / \mathrm{M}$ ratio measured prior to gene transfer. In sharp contrast, injured carotids expressing A20 showed a remarkable reduction of their $\mathrm{I} / \mathrm{M}$ ratio to $0.49 \pm 0.06(n=7 ; P=0.0003$ vs. NT and $P=0.008$ vs. rAd. $\beta$-gal; Fig. 7A). Expression of the transgene started rapidly, was optimal 3 to 5 days after gene transfer and was detected to a depth of 3-4 cells within the neointima as demonstrated by $\mathrm{X}$-gal staining. Expression of A20 was confirmed by semiquantitative RT-PCR (Fig. $7 B$ ). We then evaluated by immunohistochemistry the rate of proliferation (KI67) and apoptosis (TUNEL) in vessels prior to gene transfer and at $28+$ $1,28+3,28+5$ and $28+7$ days after gene transfer. Increased proliferation of neointimal SMC was detected in NT and rAd. $\beta$-gal transduced SMC at day $28+$ 1, as depicted by increased KI67 immunostaining in the first layers of the neointima, indicating that mere re-exposure and saline infusion of neointimal lesions led to some SMC injury. In contrast, no KI67 immunoreactivity was detected in A20-expressing SMC confirming that the potent antiproliferative effect demonstrated in medial SMC equally applied, in vivo, to neointimal SMC (Fig. $7 C, n=3$ ). No significant apoptosis was detected at day 28 (Control) nor at day $28+1$ in any of the groups studied. Apoptosis was however drastically increased in neointimal SMC of rAd.A20 transduced vessels at days $28+3$ and $28+5$ reaching $55.7 \pm 4.3$ apoptotic cells/section $(n=4)$. In contrast, the number of apoptotic cells/section was much lower reaching $11.2 \pm 1.6$ and $9.1 \pm 3.5$, in NT and rAd. $\beta$-gal transduced carotids, respectively $(P=0.0001$ vs. NT and $P<0.0001$ A20 rAd. $\beta$-gal; $n=3$; Fig. $7 C$ ). Sequential analysis of A20 expressing carotids at days $28+1,28+$ $3,28+5$ and $28+7$ showed that neointimal SMC apoptosis peaked at $28+3$ and was no longer detected by $28+7$, at which point most of the neointima had regressed $(n=3-4$, Fig. $7 D)$. This data clearly demonstrates that the novel proapoptotic function of A20 does indeed translate in vivo, but appears restricted to neointimal SMC. SMC of the medial/contractile phenotype are not susceptible to A20-mediated apoptosis. Correlating with our in vitro data implicating NO and iNOS in A20-mediated SMC apoptosis; expression of iNOS was increased in A20 expressing carotids and
Control

H\&E

$100 \mathrm{X}$
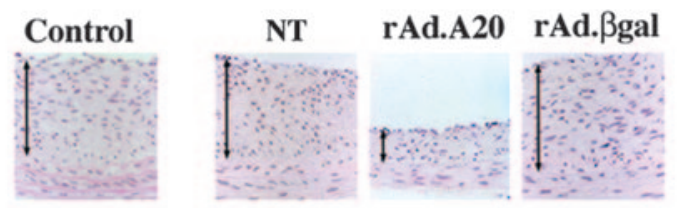

B

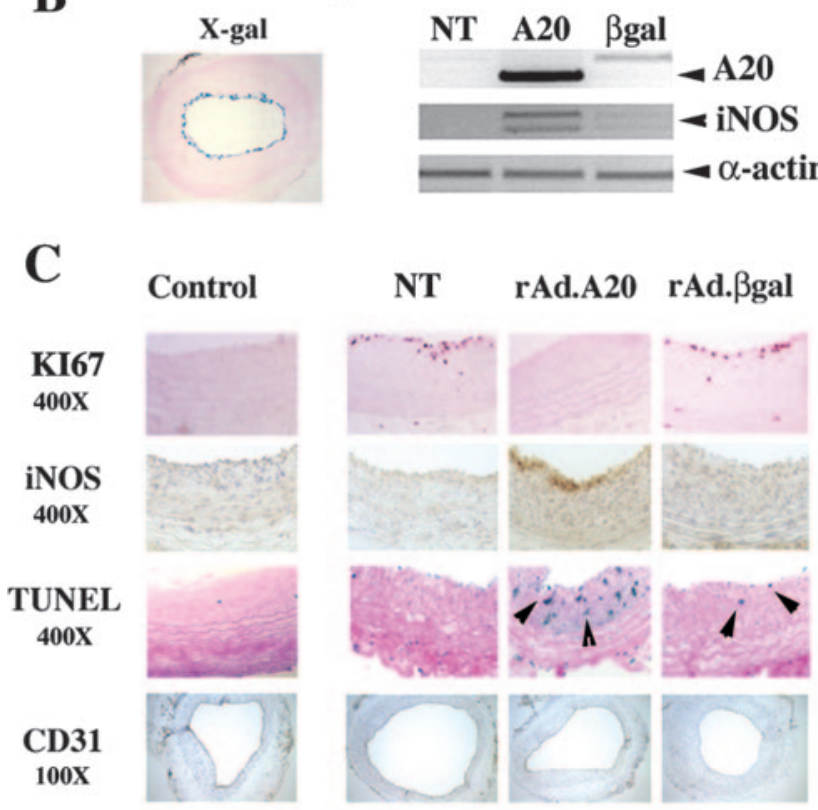

Day 28+3

D
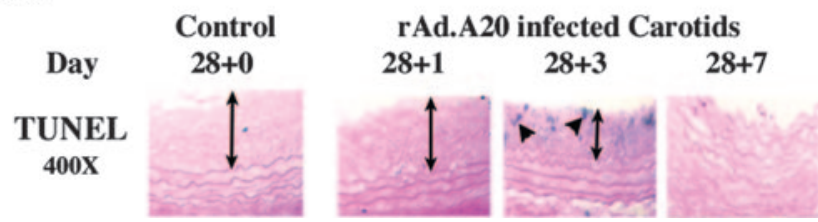

Figure 7. Evaluation of $\mathrm{I} / \mathrm{M}$ ratio on H\&E-stained rat carotid arteries sections at 28 and $28+14$ days after balloon angioplasty demonstrates regression of neointima in rAd.A20 transduced vessels compared to NT and rAd. $\beta$-gal transduced vessels. Arrows define the neointima. $(400 \times)$ A) Expression of the transgenes within the neointima is confirmed at day $28+3$ by X-gal staining $(\beta$-gal) and semiquantitative RT-PCR (A20). A20 infected vessels show also higher iNOS mRNA levels relative to NT and rAd. $\beta$-gal transduced vessels (semiquantitative RT-PCR) $(B)$. Immunohistochemistry performed at day $28+1$ shows increased KI67 positive cells (purple dots) in NT and rAd. $\beta$-gal transduced vessels while no KI67 immunostaining is detected in A20 expressing vessels $(C)$. Moderate iNOS immunoreactivity is detected in the first layers of the neointima of NT and rAd. $\beta$-gal transduced vessels contrasting with significant iNOS immunostaining in rAd.A20 transduced vessels at day $28+1(C)$. Endothelial cell integrity is maintained in NT and rAd.A20 transduced vessels as determined by CD31 contrasting with a significant loss of CD31 staining in rAd. $\beta$-gal transduced vessels at day $28+1(C)$. Increased TUNEL positive cells are detected at day $28+3$ within the neointima of A20 expressing vessels compared to NT and rAd. $\beta$-gal transduced vessels $(C)$. Sequential analysis of neointimal SMC apoptosis in rAd.transduced vessels, using TUNEL staining, demonstrates no apoptosis at $28+$ 1 days that drastically increases at day $28+3$ and is no longer detected by day $28+7(D)$. Sections of vessels retrieved 28 days after balloon angioplasty injury were used as controls. Representative sections are shown $(100 \times$ and $400 \times)$. 
correlated with increased iNOS mRNA as detected by semiquantitative RT-PCR (Fig. 7B, C). iNOS immunoreactivity scored at $1.8 \pm 0.06$ in the first few layers of the neointima of rAd.A20 expressing vessels at day $28+$ 1 , antedating the increase in apoptosis. In contrast, iNOS immunoreactivity was significantly lower in NT and rAd. $\beta$-gal transduced vessels with scores reaching $1.2 \pm 0.1$ in both groups $(P=0.004 ; n=3$; Fig. $7 C)$.

NT vessels and vessels transduced with rAd.A20 displayed no significant EC loss at day $28+1$ with CD31 positive luminal staining detected in $98.7 \pm 1.2 \%$ and $89.1 \pm 4.1 \%$, respectively $(n=4)$. In contrast, CD31 luminal staining was decreased to $23.2 \pm 0.7 \%$ in rAd. $\beta$-gal infected vessels, presumably as a consequence of adenoviral toxicity $(P=0.0004$ vs. NT and $P=0.004$ vs. rAd.A20; $n=4$; Fig. $7 C$ ).

\section{DISCUSSION}

Increased SMC proliferation and acquisition of a proinflammatory phenotype are central features associated with the development of neointimal lesions. We used the balloon injury model to study whether inhibition of multiple proinflammatory mediators by targeting a central component of the proatherogenic signaling cascades in SMC, namely NF- $\mathrm{B}$, might curb neointima formation. NF- $\mathrm{B}$ is required for the activation and proliferation of SMC in vitro and for the formation of atherosclerotic plaques in vivo (17). We have previously demonstrated that A20 is a potent inhibitor of NF- $\mathrm{B}$ including in EC $(12,13)$. In this study, we questioned whether A20 retains this function in SMC.

We demonstrate that expression of A20 in SMC inhibits NF- $\kappa$ B activation upstream of I $\mathrm{B} \alpha$ degradation. This results in subsequent inhibition of NF-кBdependent, proinflammatory, proatherogenic proteins such as MCP-1 and ICAM-1. The incidence and severity of vascular plaques in the atherosclerosis-prone, ApoEdeficient mice are decreased when MCP-1 is blocked and in ICAM-1 deficient mice $(27,28)$. Demonstration of this potent anti-inflammatory function of A20 in SMC qualifies its therapeutic potential for the prevention of neointima formation (29).

Moreover, overexpression of A20 in SMC inhibits their progression through the cell cycle by up-regulating the expression of the CDKI, p21 ${ }^{\text {wafl }}$ as well as its transcription activator, p53 before addition of FBS as well as leading to a paradoxical increase of CDKI p2 $7^{\text {kip } 1}$ levels after addition of FBS, enhancing the "brakes" on cell cycle progression. The mechanism(s) by which A20 leads to increased $\mathrm{p} 53 / \mathrm{p} 21^{\text {wafl }}$ and $\mathrm{p} 27^{\mathrm{kip} 1}$ expression remains to be determined. We have recently demonstrated that $\mathrm{p} 27^{\mathrm{kip} 1}$ is a target gene for the Forkhead transcription factors belonging to the FoxO subfamily and can be modulated to inhibit SMC proliferation and neointimal hyperplasia (30). An effect of A20 on Forkhead transcription factors resulting in the up-regulation of $\mathrm{p} 27^{\mathrm{kip} 1}$ is being investigated. Alternatively, p53 and CDKI p21 ${ }^{\text {wafl }}$ and p2 $7^{\text {kip } 1}$ may be the target of the ubiquitin-editing functions of A20, possibly leading to their decreased degradation in the proteasome (31). This would be consistent with the described regulation of $\mathrm{p} 53$ and $\mathrm{p} 21^{\text {wafl }}$ protein levels by ubiquitination $(32,33)$. This hypothesis is being investigated. However, the fact that SMC overexpressing I $\mathrm{K} \mathrm{B} \alpha$ demonstrate an identical pattern of increased $\mathrm{p} 27^{\mathrm{kip} 1}$ and $\mathrm{p} 53 / \mathrm{p} 21^{\text {wafl }}$ and a comparable decrease in FBS driven SMC proliferation, suggests that A20-mediated inhibition of SMC proliferation could also result from blockade of NF-кB, considered an essential mediator of SMC proliferation (17).

From a therapeutic standpoint, these results indicate that by combining anti-inflammatory and antiproliferative functions, A20 fulfills two criteria required for the prevention of neointima formation. The A20-mediated benefit is remarkably sustained for more than 28 days despite limited expression of the transgene, indicating that the process of vascular remodeling is determined very early after acute injury.

Expression of A20 in medial SMC after balloon angioplasty led to accelerated re-endothelialization of the injured vessels occurring $1 \mathrm{wk}$ prior to that achieved in rAd. $\beta$-gal treated vessels. This effect may reflect decreased inflammation in A20 expressing vessels facilitating healing processes including proliferation of neighboring EC or seeding and differentiation of circulating progenitor EC at the site of injury (34). It may also be the result of the well-described proangiogenic effect of NO, produced by A20 transduced SMC (35). Alternatively, quicker re-endothelialization in A20 expressing vessels may relate to a novel pro-proliferative function of A20 in EC that could have been transduced at the edge of the lesion. Regardless of mechanisms, limited EC loss and accelerated re-endothelialization adds to the beneficial effect of A20 on vascular healing (36). Indeed, seeding of injured vessels with EC or fibroblasts after balloon angioplasty provides a "dressing" that limits entry of circulating monocytes and $\mathrm{T}$ cells hence decreasing inflammation and subsequent neointimal hyperplasia (37).

In addition to increased SMC proliferation, deregulated SMC apoptosis is a key contributor to neointimal lesions $(3,38,39)$. Restenosis following balloon angioplasty in humans is associated with decreased apoptosis of neointimal SMC reflecting failure of apoptotic pathways to mediate neointimal regression $(40,41)$. Promoting apoptosis of neointimal SMC is a logical therapeutic avenue to achieve regression of neointima. Our data demonstrates that overexpression of A20, an antiapoptotic protein in EC and other cell types, unexpectedly sensitizes SMC, in vitro, to apoptosis triggered by two key proinflammatory mediators associated with a proatherogenic environment: cytokines and Fas/FasL cognate interactions $(42,43)$. The proapoptotic function of A20 in SMC is twice higher than that achieved in I $\mathrm{B} \alpha$-transduced SMC. In addition, coexpression of the NF-кB-dependent, antiapoptotic bcl protein A1 (whose expression is equally blunted by $\mathrm{I \kappa} \mathrm{B} \alpha$ and $\mathrm{A} 20$ overexpression) rescues IкB $\alpha$ but not A20-expressing SMC 


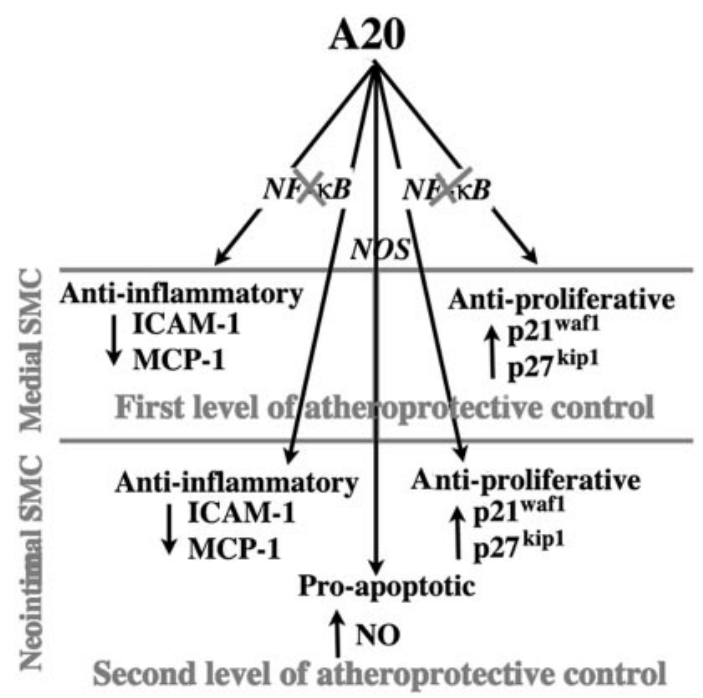

Figure 8. A20 affords two levels of atheroprotective control. First, expression of A20 in medial SMC prevents neointima formation by shutting down inflammatory and proliferative responses of SMC. Second, SMC that evade this first control and localize to the neointima are sensitized by A20 to apoptosis via a NO-dependent mechanism, hence leading to regression of neointima.

from apoptosis (21). Together, these data argue that this novel proapoptotic effect of A20 is independent from NF-кB inhibition.

Rather, A20 promotes SMC apoptosis through a NO-dependent mechanism. Blockade of NO production reverts the sensitizing effect of A20 on cytokinemediated apoptosis. A20-mediated enhancement of NO production has not been previously described and did not manifest in the antiproliferative functions of A20 in SMC nor in its antiapoptotic function in EC, pointing to refined cell type specificity of A20 functions. NO may promote SMC apoptosis through several mechanisms including up-regulation of the death receptor Fas, activation of matrix metalloproteinases, inhibition of NF- $\mathrm{KB}$ and its dependent prosurvival genes, peroxynitrite anion-mediated disruption of mitochondrial integrity and direct damaging effect on DNA $(41,44-46)$. Our data argues that direct DNA damage is likely to be the dominant molecular target for A20/NO-mediated apoptosis in our system.

In vivo, the proapoptotic function of $\mathrm{A} 20$ in SMC does not manifest when A20 is expressed in medial SMC immediately after balloon angioplasty. In contrast, A20 expression in the first few SMC layers of established neointimal lesions translates into a dramatic increase of neointimal SMC apoptosis 3-5 days after gene transfer leading to regression of neointimal hyperplasia. Antedating apoptosis, iNOS immunoreactivity and mRNA levels increase in A20 expressing neointimal SMC consistent with in vitro evidence demonstrating the involvement of NO in causing SMC apoptosis. iNOS is part of the SMC response to injury and is likely a major contributor to increased NO generation in A20-expressing SMC (47). We demonstrate a 2-fold increase in iNOS mRNA levels in cytokine-stimulated A20-express- ing SMC. Induction of iNOS at sites of inflammatory coronary lesions or after injury to rat carotids or pig iliac arteries inhibits neointimal hyperplasia (48). Conversely, blockade of iNOS by the NOS inhibitor $\mathrm{L}^{-}$ nitroarginine (L-NA) increases neointimal thickening in young rats subjected to balloon angioplasty (49). To clarify the contribution of iNOS in the atheroprotective effects of A20, experiments are planned to treat L-NA rats with A20 engineered carotids, subjected to balloon angioplasty. The molecular mechanisms governing A20-mediated up-regulation of iNOS mRNA are unknown and quite unexpected. Indeed, inhibition of $\mathrm{NF}-\kappa \mathrm{B}$ in other cell types such as $\beta$-cells blocks the transcription of iNOS after stimulation with cytokines (50). This could relate to increased iNOS mRNA stability and/or transcription by A20. The impact of A20 on the numerous transcription factors as well as regulatory processes, such as hypermethylation, that are involved in regulating iNOS promoter activity will be analyzed in a follow-up study $(51,52)$. The proapoptotic function of A20 appears restricted in vivo to neointimal SMC, which argues for an additional concentration of refined cell type-specific function(s) for A20. These findings are consistent with studies using antisense $\mathrm{Bcl}-\mathrm{x}_{\mathrm{L}}$ oligos whereby medial vascular $\mathrm{SMC}$ absorb antisense $\mathrm{Bcl}-\mathrm{x}_{\mathrm{L}}$ oligos with a similar efficiency as neointimal SMC, yet do not undergo apoptosis (7). Collectively, these data stress the greater resistance to apoptosis of medial SMC compared to neointimal SMC, possibly an ultimate defense mechanism to maintain vascular integrity.

In summary, we demonstrate that A20 is part of the protective response of SMC to injury and significantly contributes to vascular remodeling. It is expressed in SMC response to inflammatory stimuli to control inflammatory and proliferative responses and sensitize neointimal SMC to apoptosis. This later and unexpected function of A20 adds a therapeutic dimension to its preventive effect against neointimal hyperplasia. Our working model comprises two levels of A20 based control of neointimal lesions. First, expression of A20 in medial SMC prevents neointima formation by shutting down inflammatory and proliferative responses of $\mathrm{SMC}$ via inhibition of NF- $\mathrm{B}$ and increased expression of the CDKI p21 wafl and p2 $7^{\mathrm{kip} 1}$. Second, SMC that evade this first control and form a neointima are sensitized by A20 to apoptosis via a NO-dependent mechanism, which promotes regression of established neointimal lesions (Fig. 8). We propose that A20 based therapies hold strong promise for the prevention and cure of vascular neointimal disease including in-stent restenosis, atherosclerosis and transplant arteriosclerosis.

We wish to acknowledge Prof. Fritz H. Bach from the BIDMC for his continuous support and for critical review of this manuscript and Prof. Frank W. LoGerfo for his support and help. This research was supported in part by a grant from the Roche Organ Transplantation Research Foundation (ROTRF) to C.F. and NIH grants RO1 HL08013, RO1 HL021796 and RO1 DK063275 to C.F. C.R.L., V.I.P., G.V.S., S.T.S., and 
M.D.F. were supported in part by NIH T32 HL07734. S.D. is a recipient of fellowship grants from the INSERM, France and the Association pour la Recherche sur le Cancer (ARC) France.

\section{REFERENGES}

1. Lusis, A. J. (2000) Atherosclerosis. Nature 407, 233-241

2. Libby, P., and Pober, J. S. (2001) Chronic rejection. Immunity 14, 387-397

3. Isner, J. M., Kearney, M., Bortman, S., and Passeri, J. (1995) Apoptosis in human atherosclerosis and restenosis. Circulation 91, 2703-2711

4. Serruys, P. W., Luijten, H. E., Beatt, K. J., Geuskens, R., de Feyter, P. J., van den Brand, M., Reiber, J. H., ten Katen, H. J., van Es, G. A., and Hugenholtz, P. G. (1988) Incidence of restenosis after successful coronary angioplasty: a time-related phenomenon. A quantitative angiographic study in 342 consecutive patients at 1, 2, 3, and 4 months. Circulation 77, 361-371

5. Morice, M. C., Serruys, P. W., Sousa, J. E., Fajadet, J., Ban Hayashi, E., Perin, M., Colombo, A., Schuler, G., Barragan, P., Guagliumi, G., Molnar, F., and Falotico, R. (2002) A randomized comparison of a sirolimus-eluting stent with a standard stent for coronary revascularization. N. Engl. J. Med. 346, 17731780

6. Moussa, I., Leon, M. B., Baim, D. S., O’Neill, W. W., Popma, J. J., Buchbinder, M., Midwall, J., Simonton, C. A., Keim, E., Wang, P., Kuntz, R. E., and Moses, J. W. (2004) Impact of sirolimuseluting stents on outcome in diabetic patients: a SIRIUS (SIRolImUS-coated Bx Velocity balloon-expandable stent in the treatment of patients with de novo coronary artery lesions) substudy. Circulation 109, 2273-2278

7. Pollman, M. J., Hall, J. L., Mann, M. J., Zhang, L., and Gibbons, G. H. (1998) Inhibition of neointimal cell $b c l-x$ expression induces apoptosis and regression of vascular disease. Nature Med. 4, 222-227

8. Blanc-Brude, O. P., Yu, J., Simosa, H., Conte, M. S., Sessa, W. C., and Altieri, D. (2002) Inhibitor of apoptosis protein survivin regulates vascular injury. Nature Med. 9, 987-994

9. Sata, M., Perlman, H., Muruve, D. A., Silver, M., Ikebe, M., Libermann, T. A., Pettgen, P., and Walsh, K. (1998) Fas ligand gene transfer to the vessel wall inhibits neointima formation and overrides the adenovirus-mediated T cell response. Proc. Natl. Acad. Sci. U. S. A. 95, 11213-11217

10. Iwashina, M., Schichiri, M., Marumo, F., and Hirata, Y. (1998) Transfection of inducible nitric oxide synthase gene causes apoptosis in vascular smooth muscle cells. Circulation 98, 12121218

11. Shears, L. L. I., Kawaharada, N., Tzeng, E., Billiar, T. R., Watkins, S. C., Kovesdi, I., Lizonova, A., and Pham, S. M. (1997) Inducible nitric oxide synthase suppresses the development of allograft arteriosclerosis. J. Clin. Invest. 100, 2035-2042

12. Cooper, J. T., Stroka, D. M., Brostjan, C., Palmetshofer, A., Bach, F. H., and Ferran, C. (1996) A20 blocks endothelial cell activation through a NF-кB-dependent mechanism. J. Biol. Chem. 271, 18068-18073

13. Ferran, C., Stroka, D. M., Badrichani, A. Z., Cooper, J. T. Wrighton, C. J., Soares, M., Grey, S. T., and Bach, F. H. (1998) A20 inhibits NF- $\mathrm{B}$ activation in endothelial cells without sensitizing to TNF-mediated apoptosis. Blood 91, 2249-2258

14. Daniel, S., Arvelo, M. B., Patel, V. I., Longo, C. R., Shrikhande, G., Shukri, T., Mahiou, J., Sun, D. W., Mottley, C., Grey, S. T., and Ferran, C. (2004) A20 protects endothelial cells from TNF-, Fas-, and NK-mediated cell death by inhibiting caspase 8 activation. Blood 104, 2376-2384

15. Gimbrone, M. A. J. (1995). Vascular endothelium: an integrator of pathophysiologic stimuli in atherosclerosis. Am. J. Cardiol. 75, $67 \mathrm{~B}-70 \mathrm{~B}$

16. Longo, C. R., Arvelo, M. B., Patel, V. I., Daniel, S., Mahiou, J., Grey, S. T., and Ferran, C. (2003) A20 protects from CD40CD40 ligand-mediated endothelial cell activation and apoptosis. Circulation 108, 1113-1118

17. Bourcier, T., Sukhova, G., and Libby, P. (1997) The nuclear factor $\mathrm{k}-\mathrm{B}$ signaling pathway participates in dysregulation of vascular smooth muscle cells in vitro and human atherosclerosis. J. Biol. Chem. 272, 15817-15824

18. Kunter, U., Floege, J., von Jurgensonn, A. S., Stojanovic, T., Merkel, S., Grone, H. J., and Ferran, C. (2003) Expression of A20 in the vessel wall of rat-kidney allografts correlates with protection from transplant arteriosclerosis. Transplantation 75, 3-9

19. Clowes, A. W., Reidy, M. A., and Clowes, M. M. (1983) Mechanisms of stenosis after arterial injury. Lab. Invest. 49, 208-215

20. Storz, P., Doppler, H., Ferran, C., Grey, S. T., and Toker, A. (2005) Functional dichotomy of A20 in apoptotic and necrotic cell death. Biochem. J. 387, 47-55

21. Stroka, D. M., Badrichani, A. Z., Bach, F. H., and Ferran, C. (1999) Overexpression of A1, an NF-кB-inducible, anti-apoptotic Bcl gene inhibits endothelial cell activation. Blood $\mathbf{9 3}$ 3803-3810

22. Lee, E. G., Boone, D. L., Chai, S., Libby, S. L., Chein, J., Lodolce, J. P., and Ma, A. (2000) Failure to regulate TNF-induced NF-кB and cell death responses in A20-deficient mice. Science $\mathbf{2 8 9}$, $2350-2354$

23. Bornfeldt, K. E. (2003) The cyclin-dependent kinase pathway moves forward. Circ. Res. 92, 345-347

24. Hsieh, J. K., Kletsas, D., Clunn, G., Hughes, A. D., Schachter, M. and Demoliou-Mason, C. (2000) p53, p21 WAF1/CIP1 and MDM2 involvement in the proliferation and apoptosis in an in vitro model of conditionally immortalized human vascular smooth muscle cells. Arteriosler. Thromb. Vasc. Biol. 20, 973-981

25. Wang, B. Y., Ho, H. K., Lin, P. S., Schwarzacher, S. P., Pollman, M. J., Gibbons, G. H., Tsao, P. S., and Cooke, J. P. (1998) Regression of atherosclerosis role of nitric oxide and apoptosis Circulation 99, 1236-1241

26. Krikos, A., Laherty, C. D., and Dixit, V. M. (1992) Transcriptional activation of the TNF $\alpha$-inducible zinc finger protein, A20, is mediated by $\kappa \mathrm{B}$ elements. J. Biol. Chem. 267, 17971-17976

27. Ni, W., Egashira, K., Kitamoto, S., Kataoka, C., Koyanagi, M., Inoue, S., Imaizumi, K., Akiyama, C., Nishida, K. I., and Takeshita, A. (2001) New anti-monocyte chemoattractant protein-1 gene therapy attenuates atherosclerosis in apolipoprotein E-knockout mice. Circulation 103, 2096-2101

28. Collins, R. G., Velji, R., Guevara, N. V., Hicks, M. J., Chan, L., and Beaudet, A. L. (2000) P-Selectin or intercellular adhesion molecule (ICAM)-1 deficiency substantially protects against atherosclerosis in apolipoprotein E- deficient mice. J. Exp. Med. 191, 189-194

29. Ross, R. (1999) Atherosclerosisān inflammatory disease. N. Engl. J. Med. 340, 115-126

30. Abid, M. R., Yano, K., Guo, S., Patel, V. I., Shrikhande, G., Spokes, K. C., Ferran, C., and Aird, W. C. (2005) Forkhead transcription factors inhibit vascular smooth muscle cell proliferation and neointimal hyperplasia. J. Biol. Chem. 280, 29864-29873

31. Wertz, I. E., O'Rourke, K. M., Zhou, H., Eby, M., Aravind, L., Seshagiri, S., Wu, P., Wiesmann, C., Baker, R., Boone, D. L., Ma, A., Koonin, E. V., and Dixit, V. M. (2004) De-ubiquitination and ubiquitin ligase domains of A20 downregulate NF-kappaB signalling. Nature 430, 694-699

32. Coulombe, P., Rodier, G., Bonneil, E., Thibault, P., and $\mathrm{Me}^{-}$ loche, S. (2004) N-Terminal ubiquitination of extracellular signal-regulated kinase 3 and p21 directs their degradation by the proteasome. Mol. Cell. Biol. 24, 6140-6150

33. Yang, Y., Li, C. C., and Weissman, A. M. (2004) Regulating the p53 system through ubiquitination. Oncogene 23, 2096-2106

34. Xu, Q., Zhang, Z., Davison, F., and Hu, Y. (2003) Circulating progenitor cells regenerate endothelium of vein graft atherosclerosis, which is diminished in ApoE-deficient mice. Circ. Res. 93, e76-86

35. Cooke, J. P. (2003) NO and angiogenesis. Atheroscler. Suppl. 4, 53-60

36. Hariri, R. J., Alonso, D. R., Hajjar, D. P., Coletti, D., and Weksler, M. E. (1986) Aging and arteriosclerosis. I. Development of myointimal hyperplasia after endothelial injury. J. Exp. Med. 164, $1171-1178$

37. Gomes, D., Louedec, L., Plissonnier, D., Dauge, M. C., Henin, D., Osborne-Pellegrin, M., and Michel, J. B. (2001) Endoluminal smooth muscle cell seeding limits intimal hyperplasia. $J$. Vasc. Surg. 34, 707-715

38. Bennett, M. R., Evan, G. I., and Schwartz, S. M. (1995) Apoptosis of human vascular smooth muscle cells derived from normal vessels and coronary atherosclerotic plaques. J. Clin. Invest. 95, $2266-2274$ 
39. Rembold, C. (1996) Could atherosclerosis originate from defective smooth muscle cell death (apoptosis)? Persp. Biol. Med. 39, 405-408

40. Chan, S. W., Hegyi, L., Scott, S., Cary, N. R. B., Weissberg, P. L., and Bennett, M. R. (2000) Sensitivity to Fas-mediated apoptosis is determined below receptor level in human vascular smooth muscle cells. Circ. Res. 86, 1038-1046

41. Kockx, M. M., and Herman, A. G. (2000) Apoptosis in atherosclerosis: beneficial or detrimental? Cardiovasc. Res. 45, 736-746

42. Schaub, F. J., Han, D. K. M., Liles, W. C., Adams, L. D., Coats, S. A., Ramachandran, R. K., Seifert, R. A., Schwartz, S. M., and Bowen-Pope, D. F. (2000) Fas/FADD-mediated activation of a specific program of inflammatory gene expression in vascular smooth muscle cells. Nature Med. 6, 790-796

43. Schreyer, S. A., Peschon, J. J., and Leboeuf, R. C. (1996) Acclerated atherosclerosis in mice lacking tumor necrosis factor receptor p55. J. Biol. Chem. 271, 26174-26178

44. Geng, Y. J., Muszynski, M., HAnsson, G. K., and Libby, P. (1996) Apoptosis of vascular smooth muscle cells induced by in vitro stimulation with Interferon- $\gamma$, tumor necrosis factor- $\alpha$, and interleukin-1ß. Arterioscler. Thromb. Vasc. Biol. 16, 19-27

45. Fukuo, K., Hat, S., Suhara, T., Nakahashi, T., Shinto, Y., Tsujimoto, Y., Morimoto, S., and Ogihara, T. (1996) Nitric oxide induces up-regulation of Fas and apoptosis in vascular smooth muscle cells. Hypertension 27, 823-826

46. Peng, H. B., Libby, P., and Liao, J. K. (1995) Induction and stabilization of IкB- $\alpha$ by nitric oxide mediates inhibition of NF-кB. J. Biol. Chem. 270, 14214-14219
47. Hansson, G. K., Geng, Y. J., Holm, J., Hardhammar, P., Wennmalm, A., and Jennische, E. (1994) Arterial smooth muscle cells express nitric oxide synthase in response to endothelial injury. J. Exp. Med. 180, 733-738

48. Fukumoto, Y., Shimokawa, H., Kozai, T., Kadokami, T., Kuwata, K. Yonemitsu, Y., Kuga, T., Egashira, K., Sueishi, K., and Takeshita, A. (1997) Vasculoprotective role of inducible nitric oxide synthase at inflammatory coronary lesions induced by chronic treatment with interleukin-1beta in pigs in vivo. Circulation 96, 3104-3111

49. Chen, L., Daum, G., Fischer, J. W., Hawkins, S., BochatonPiallat, M. L., Gabbiani, G., and Clowes, A. W. (2000) Loss of expression of the beta subunit of soluble guanylyl cyclase prevents nitric oxide-mediated inhibition of DNA synthesis in smooth muscle cells of old rats. Circ. Res. 86, 520-525

50. Grey, S. T., Arvelo, M. B., Hasenkamp, W., Bach, F. H., and Ferran, C. (1999) A20 inhibits cytokine-induced apoptosis and nuclear factor $\mathrm{\kappa B}$-dependent gene activation in islets. J. Exp. Med. 190, 1135-1145

51. Beck, K. F., and Sterzel, R. B. (1996) Cloning and sequencing of the proximal promoter of the rat iNOS gene: activation of NFkappaB is not sufficient for transcription of the iNOS gene in rat mesangial cells. FEBS Lett. 394, 263-267

52. Yu, Z., and Kone, B. C. (2004) Hypermethylation of the inducible nitric-oxide synthase gene promoter inhibits its transcription. J. Biol. Chem. 279, 46954-46961

Received for publication September 15, 2005. Accepted for publication March 14, 2006. 